\title{
ARQUIVOS DE NEURO-PSIQUIATRIA
}

\section{DIAGNOSTICO DIFERENCIAL DAS DISTROFIAS MUSCULARES COM REFERENCIA ESPECIAL ÀS ALTERAÇõES ENZIMÁTICAS}

\author{
H. HEICK
}

G. LAUDAHN

Nos últimos anos vem sendo feitos esforços visando esclarecer a patogenia das miopatias, especialmente das distrofias musculares progressivas, com a esperança de obter rumos para terapêutica eficaz. Desde 1961 nos dedicamos ao assunto e nos propomos, agora, a expor alguns resultados de nossas pesquisas. Inicialmente comentaremos alguns dos caracteres dos diferentes tipos de miopatias, assim como a freqüência e as variações clínicas das distrofias musculares progressivas e hereditárias, salientando as relações entre os quadros clínicos e os diferentes tipos de transmissão genética. Passaremos, depois, aos resultados que obtivemos com o estudo das alterações enzimáticas. Ao lado das alterações enzimáticas do sôro sangüineo estudamos, também e simultâneamente com a histopatologia, as alterações enzimáticas do tecido muscular. Em alguns casos fizemos estas pesquisas em várias fases da moléstia visando esclarecer a patogenia do processo. Estas pesquisas também foram utilizadas na avaliação de certas medidas terapêuticas.

Ainda não é uniforme a classificação das distrofias musculares progressivas porque nem sempre os clínicos conseguem ajustar seus casos nos limites mais ou menos rígidos da classificação genética que é, teòricamente, a mais acertada. A dificuldade é maior nos casos isolados nos quais nem sempre é possivel determinar o fator hereditário responsável. Quando esta determinação é viável podem ser classificados três tipos principais de dis-

Trabalho da Clinica Neurológica do Hospital Estadual Rudolf Wirchow (Berlim, Alemanha), apresentado ao Departamento de Neurologia da Associação Paulista de Medicina em 12 de setembro de 1966.

Nota da Redação - Este trabalho, redigido em língua alemã, foi vertido para o castelhano na sua totalidade e, na parte relativa ao texto, também para o português. Isso explica o fato du texto ser impresso em português, ao passo que os dizeres das ilustrações continuam em castelhano. 
trofias musculares progressivas que se desenvolvem à custa de diferentes fatôres hereditários.

Por um fator recessivo x-cromosômico ligado ao sexo (rezessive geschlechtgebundener $\mathrm{x}$-chromosomaler Erbgang) é transmitida a distrofia progressiva tipo Duchenne, enfermidade que acomete apenas meninos, que se inicia nos primeiros anos de vida e que, em geral, é ràpidamente progressiva. É considerada como a mais freqüente e a mais grave das distrofias musculares progressivas, sendo às vêzes errôneamente denominada como miopatia de tipo pseudo-hipertrófico. A tabela 1 mostra que pseudohipertrofias das panturrilhas freqüentemente não ocorrem nas distrofias musculares tipo Duchenne; por outro lado, êstes aparentes aumentos das massas musculares podem ocorrer em todos os tipos de distrofias musculares, o que lhes tira todo o valor como elemento diagnóstico.

Também é freqüente a distrofia muscular tipo cintura dos membros (Gliederguerteltyp) que acomete individuos de ambos os sexos, pois o distúrbio atinge cromosomas não ligados ao sexo. Como no tipo Duchenne, o enfraquecimento e a distrofia musculares se iniciam, em geral, na cintura pélvica, e, mais raramente, na cintura escapular (tabela 1). O início tardio e a evolução mais lenta desta distrofia constituem a regra, ocorrendo, entretanto, exceções, como é o caso de meninas acometidas em tenra idade e que ficam logo impossibilitadas de andar. Cabe relembar aqui que, em meninas, o diagnóstico de distrofia muscular tipo Duchenne, às vêzes aventado, é insustentável do pontc de vista genético.

Mais raro é o tipo autossômico dominante que, de regra, corresponde ao que, em clínica, se designa como distrofia muscular tipo fácio-escápuloumeral. Os doentes chamam a atenção por terem os lábios protundentes ou atrofiados e inertes ou, ainda, pela deficiência no fechamento das fendas palpebrais. Segundo Becker as distrofias têm inicio, sempre, na cintura escapular, só acometendo mais tarde os músculos da cintura pélvica e os femurais. No entanto pudemos observar em indivíduos de três geraçōes da mesma familia - tratando-se, portanto, de hereditariedade dominante - o início da distrofia muscular na cintura pélvica. Aventamos que êstes casos se enquadrem em um quarto tipo de distrofia muscular progressiva (grupo IV da tabela 1).

Desde 1961 até junho de 1966 tivemos oportunidade de examinar 221 pacientes com distrofia muscular progressiva. Na tabela 1 nossos casos foram divididos conforme o tipo da moléstia, sendo indicados a idade e o sexo dos pacientes, a data do inicio da enfermidade, a presença de pseudo-hipertrofias, a região onde se iniciaram o enfraquecimento e a distrofia muscular, a hereditariedade.

Essa tabela dispensa comentários. Entretanto, alguns itens merecem ser salientados. Assim, em 89 de 125 meninos com distrofia muscular tipo Duchenne, com início precoce e evolução rápida, não pôde ser assinalada a ocorrência da moléstia em outros membros da família, o que é explicável pelo elevado índice de mutação neste tipo. Por outro lado, o acometimento 
tardio e a evolução relativamente lenta que caracterizam as distrofias de tipo cintura dos membros e de tipo fácio-escápulo-umeral não foram assinalados em todos os nossos casos, pois, em 15 dêles, os pacientes foram acometidos antes dos 5 anos de idade e a evolução foi rápida.

$\mathrm{Na}$ última rubrica constante da tabela 1, de acôrdo com os critérios de Thompson e Vignos sôbre a diminuição de funções nas formas do tipo cintura pélvica e sôbre a duração da moléstia nos tipos I e II, calculamos um quociente de progresso cuja altura é proporcional à rapidez da evolução da moléstia.

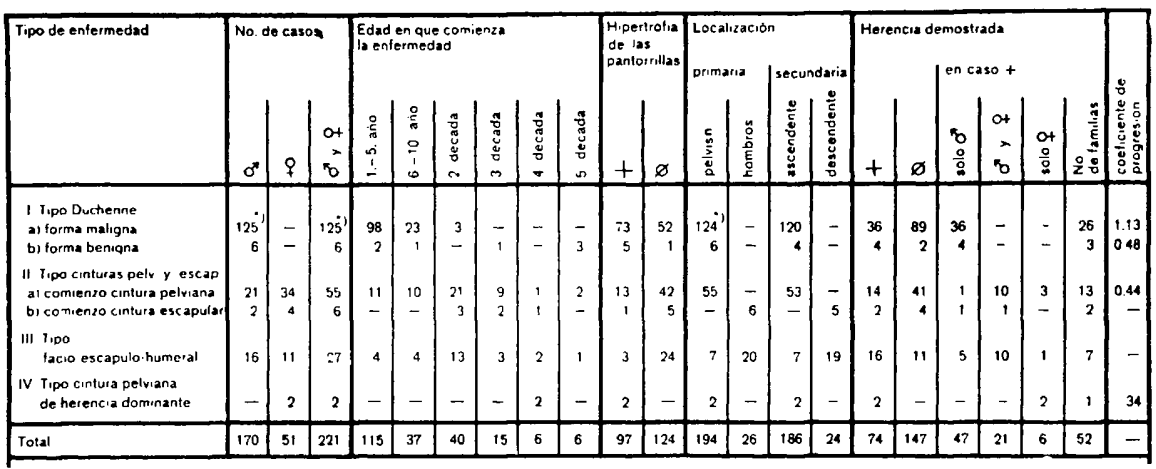

Tabela 1 - Dados clinicos e genéticos dos 221 casos de distrofia muscular progressiva estudados. O grau de progressão da moléstia é dado pelo quociente entre a diminuição da funçäo (grau de 1 a 11, segundo Thompson e Vignos) e o tempo de duração da moléstia (em anos): * caso em fase pré-clínica.

Desde que Sibley e Lehninger, em 1949, verificaram aumento do teor de aldolase no sôro sangüineo em um caso de distrofia muscular progressiva, foram publicados numerosos trabalhos mostrando modificaçōes das atividades enzimáticas nas distrofias musculares progressivas, não só no referente à aldolase como também em relação a outras enzimas. No início de nossas pesquisas os estudos mais completos que tinham sido relatados até então eram de Dreyfus e Shapira, os primeiros a mostrar que as proteinas enzimáticas cujo teor aumenta no sôro sangüineo em tais eventualidades são oriundas da musculatura distrófica. Deve-se a Ebashi, em 1959, a identificação da creatinofosfoquinase como enzima citoplasmática existindo preponderantemente na musculatura. Essa identificação e a verificação de que o teor desta enzima aumenta no sôro sangüineo de pacientes com musculatura distrófica, representam importantes contribuições para o diagnóstico diferencial das miopatias.

$\hat{E}$ verdade que logo depois foi demonstrado que aumentos das atividades sôro-enzimáticas são encontrados, não sỏmente nas distrofias musculares progressivas, mas também na miotonia distrófica e em miopatias adquiridas como sejam, por exemplo, as polimiosites agudas e crônicas e, mesmo, nas alterações miopáticas do lupus eritematoso. Numerosos estudos, no entanto, 
levaram a reconhecer que os aumentos da atividade sôro-enzimática são mais precípuos nas distrofias musculares progressivas, especialmente no tipo Duchenne.

Além disso, algumas investigações pareciam indicar que, em casos de distrofias musculares de origem neural ou medular, não ocorrem modificações das atividades enzimáticas no sôro sangüíneo. Se assim fôsse, a pesquisa da atividade enzimática permitiria o diagnóstico diferencial entre distrofias musculares miopáticas e neuropáticas, constituindo recurso de grande valor nos casos de diagnóstico difícil, como pode acontecer com a chamada atrofia muscular pseudo-miopática de tipo proximal, descrita por Kugelberg e Welander.

Estudamos a atividade sôro-enzimática em numerosos casos de distrofias musculares miopáticas e em muitos casos de distrofias musculares por afecções medulares, entre os quais 22 com atrofia muscular infantil do tipo Werdnig-Hoffmann e 23 com atrofia muscular pseudo-miopática tipo Kugelberg-Welander. Em todos os casos determinamos, no sôro sangüineo, a atividade da aldolase (Ald), da creatinofosfoquinase (CPK), das transaminases glutâmino-oxalacética e glutâmino-pirúvica (GOT e GPT), das desidrogenases láctica e málica ( $\mathrm{LDH}$ e $\mathrm{MDH}$ ). Em alguns casos verificamos a atividade sérica de outras enzimas.

A figura 1 mostra as diferenças nos teores dessas enzimas nos três tipos principais de distrofias musculares progressivas e hereditárias. Con-

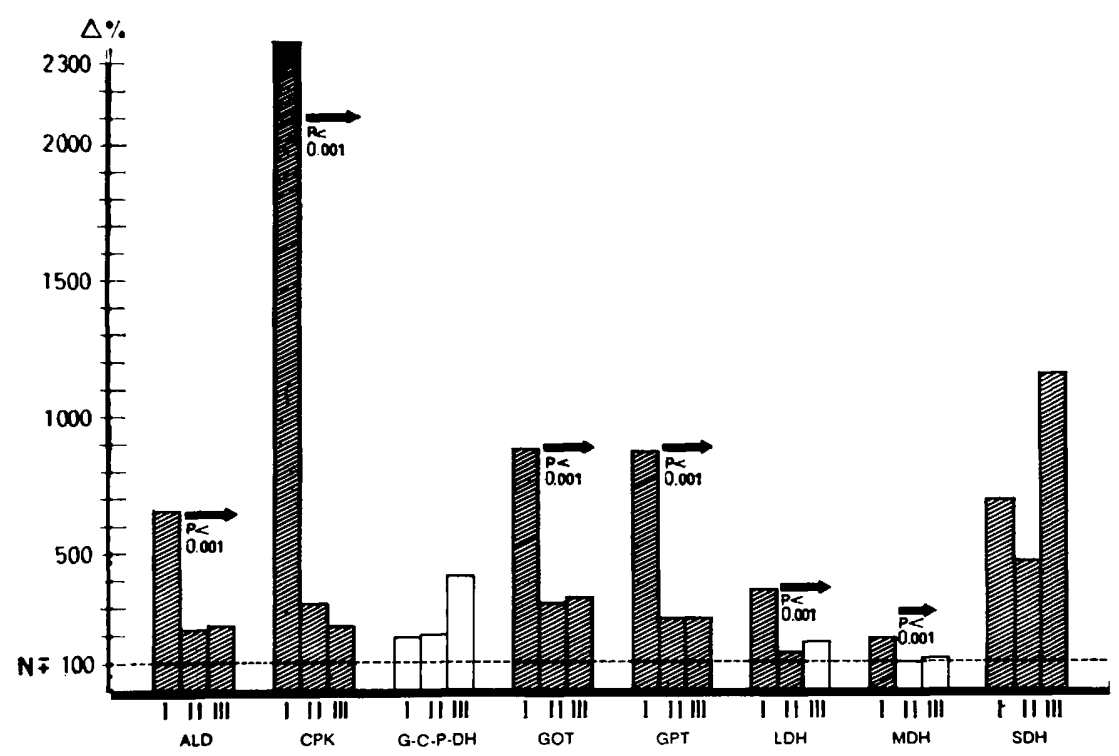

Fig. 1 - Percentagens dos aumentos das atividades sôro-enzimáticas nos três tipos de distrofia muscular progressiva hereditária: tipo Duchenne (98 casos), tipo cinturas escapular e pélvica (58 casos), tipo facio-escápulo-umeral (18 casos). Os aumentos significantes foram assinalados em colunas riscadas. 
siderando os valôres médios, anotamos as percentagens de divergência em relação à normalidade nesses três tipos de afecção. Quando fizemos êsse diagrama o número de casos era menor que atualmente; entretanto, os exames feitos em pacientes observados ulteriormente não modificaram substancialmente os resultados gerais. Verificamos que, nos três tipos de distrofia muscular progressiva e hereditária, ocorrem aumentos significativos de Ald, CPK, GOT, GPT e, também, de desidrogenase sorbítica (SDH). Deve ser salientado que os maiores teores enzimáticos ocorrem na distrofia tipo Duchenne, sendo significante a diferença entre os teores obtidos nesta afecção e aquêles encontrados no tipo da cintura dos membros e no tipo fácio-escápulo-umeral, especialmente no que se refere à atividade da creatinofosfoquinase.

O valor das dosagens de enzimas no sôro sangüineo para o diagnóstico diferencial pode ser deduzido dos resultados que constam da tabela 2, na qual registramos, em percentagens, a intensidade dos aumentos em relação à normalidade, para mostrar o quanto é incerta a valorização de resultados isolados para o diagnóstico diferencial. Dos dados contidos nessa tabela destacaremos os referentes à aldolase e à creatinofosfoquinase.

\begin{tabular}{|l|l|l|l|l|}
\hline Enzima & $\begin{array}{l}\text { I } \\
\text { Tipo } \\
\text { Duchenne }\end{array}$ & $\begin{array}{l}\text { II } \\
\text { Tipo } \\
\text { cinturas } \\
\text { oscapular } \\
\text { y polviana }\end{array}$ & $\begin{array}{l}\text { III } \\
\text { Tipo } \\
\text { facio- } \\
\text { escapulo- } \\
\text { humeral }\end{array}$ & Total \\
& $\mathrm{N}=68$ & $\mathrm{~N}=60$ & $\mathrm{~N}=\mathbf{8}$ & $\mathrm{N}=138$ \\
\hline ALD & $75 \%$ & $52 \%$ & $50 \%$ & $63 \%$ \\
CPK & $62 \%$ & $32 \%$ & $13 \%$ & $46 \%$ \\
G-6-P-DH & $25 \%$ & $30 \%$ & $50 \%$ & $29 \%$ \\
GOT & $94 \%$ & $73 \%$ & $75 \%$ & $84 \%$ \\
GPT & $88 \%$ & $61 \%$ & $75 \%$ & $76 \%$ \\
MDH & $74 \%$ & $35 \%$ & $38 \%$ & $54 \%$ \\
SDH & $57 \%$ & $20 \%$ & $25 \%$ & $31 \%$ \\
& $55 \%$ & $44 \%$ & $63 \%$ & $51 \%$ \\
\hline
\end{tabular}

Tabela 2 - Freqüencia do aumento das atividades sôroenzimáticas em função dos valôres normais em 136 pacientes com distrofia muscular progressiva.

Devemos dizer desde logo que os teores de aldolase que registramos concordam com os resultados obtidos por outros autores. Em 200 casos de distrofia muscular progressiva verificamos que, embora no tipo Duchenne os aumentos sejam mais freqüentes e maiores, nos tipos da cintura dos membros e fácio-escápulo-umeral também podem ocorrer aumentos consideráveis. Por outro lado, verificamos que, em alguns casos do tipo Duchenne, os valôres sôro-enzimáticos podem ser normais. Em outras formas de distrofias musculares (doença de Werdnig-Hoffmann, doença de KugelbergWelander, distrofia espinhal progressiva tipo Aran-Duchenne, esclerose lateral amiotrófica, distrofias musculares neuropáticas) também encontramos, com relativa freqüência, aumento do teor sérico da aldolase, embora tais aumentos não sejam muito elevados. 
Em relação à creatinofosfoquinase verificamos que, ocasionalmente, não há aumento desta enzima em casos de distrofia muscular progressiva tipo Duchenne e que, por outro lado, tanto nos outros tipos de distrofias musculares progressivas como nas distrofias musculares secundárias a neuropatias ou a mielopatias, podem ser encontrados teores às vêzes bem elevados. $\mathrm{Na}$ figura 2 expomos os resultados que obtivemos com as dosagens de creatinofosfoquinase em 22 casos de atrofia muscular infantil tipo WerdnigHoffmann e em 21 casos de atrofia espinhal pseudo-miopática de KugelbergWelander, comparando-os com os valôres máximos desta enzima em crianças. Em poucos casos de atrofia infantil tipo Werdnig-Hoffmann foram encontrados discretos aumentos do teor de creatinofosfoquinase. Nos pacientes mais idosos, enquadráveis no tipo Kugelberg-Welander, foram encontrados aumentos mais significantes desta enzima, mostrando que, em casos de distrofias musculares de origem medular, se desenvolvem, na musculatura, processos cujos efeitos sôbre as enzimas são idênticos aos que ocorrem nas miopatias. Aliás, é sabido que, na vigência de processos medulares, as fibras musculares ainda não totalmente atrofiadas apresentam-se, do ponto de vista histopatológico, com aspectos idênticos aos encontráveis nas miopatias. Mittelbach escreveu, há pouco tempo, monografia sôbre esta questão.

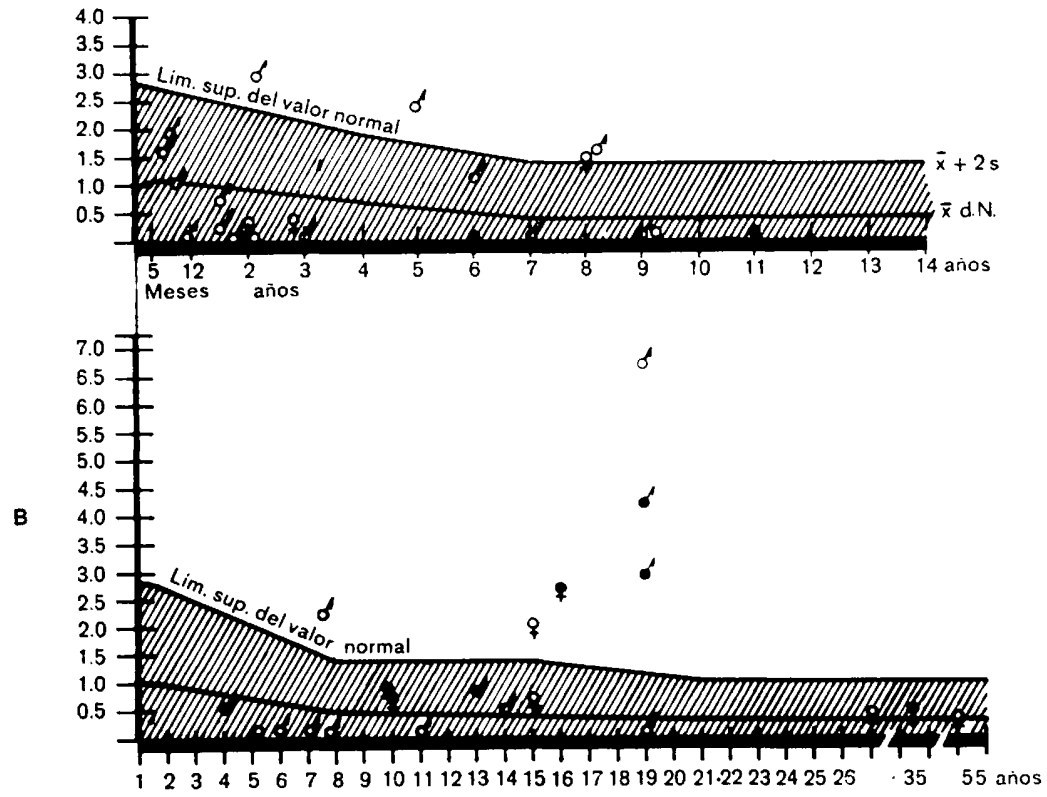

Fig. 2 - Curvas dos valôres de creatinofosfoquinase sérica de acôrdo com a idade dos pacientes e considerando os valôres normais por idade (segundo Metz e resultados de investigaçöes pessoais): em A, em $2 z$ casos de atrofia espinhal infantil de Werdnig-Hoffmann (valor médio 0,73 U.I.; idade média 3,6 anos) não há aumento significativo da atividade enzimática; em $B$, em 21 casos de atrofia muscular pseudomiopática de Kugelberg-Welander (valor médio 1,2 U.I.; idade média 14,9 anos) há aumento significativo da atividade enzimática. 
Expondo e comentando nossos resultados, não queremos negar o auxílio valioso que a determinação dos teores enzimáticos no sôro sangüíneo pode prestar para o diagnóstico das miopatias. Entretanto, tais resultados mostram o cuidado que se deve ter na valorização dêstes achados laboratoriais, pois aumentos isolados dos teores sôro-enzimáticos não têm especificidade.

A verificação, feita por Dreyfus e Shapira, de que as enzimas cujo teor aumenta no sôro sangüineo provêm da musculatura distrófica e a hipótese dai desenvolvida e aceita pela maioria dos pesquisadores, de que uma das causas essenciais do perecimento das fibras musculares residiria em um distúrbio da permeabilidade da célula muscular, nos levaram a fazer pesquisas nesta direção.

Um dêsses estudos refere-se às alterações quantitativas das sôro-enzimas no decorrer da moléstia muscular. Como pode ser visto na figura 3 , na qual constam resultados obtidos em casos de distrofia muscular tipo Duchenne, a hiperatividade enzimática, com exceção apenas da $\mathrm{MDH}$, diminui paulatinamente com o decorrer da doença, podendo até normalizar-se no período final. Pudemos documentar que os teores de aldolase diminuem entre o $1 .^{\circ}$ e o $28 .^{\circ}$ ano de idade. Fato idêntico foi observado quanto aos teores de creatinofosfoquinase, embora a curva decrescente desta enzima seja mais lenta do que a da aldolase. $\hat{E}$ de supor que êste decréscimo progressivo das atividades sôro-enzimáticas seja condicionado ao progressivo esgotamento do conteúdo proteino-enzimático das células musculares, esgotamento êste que acompanha a diminuição progressiva da substância muscular, como o demonstram os exames histológicos em diferentes fases da moléstia.

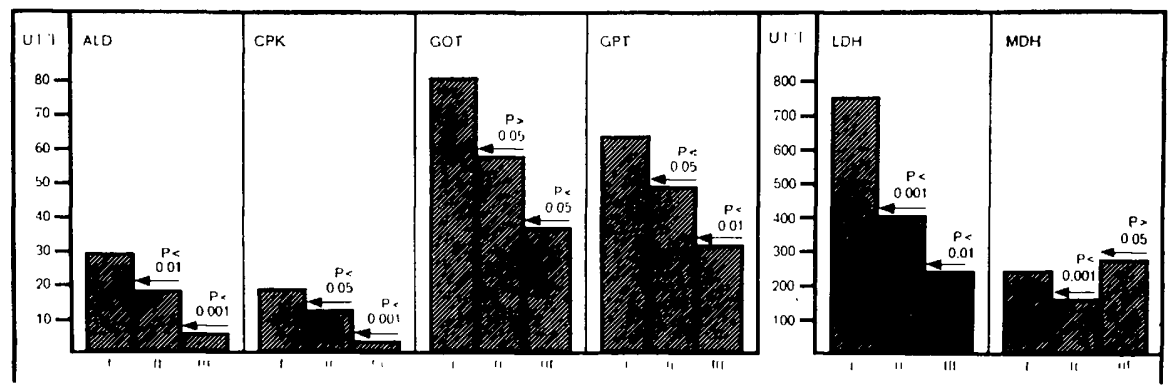

Fig. 3 - Oscilações das atividades sôro-enzimáticas em função da duração da enfermidade em 116 casos de distrofia muscular progressiva tipo Duchenne. Os dados se referem aos valôres médios de cada grupo: grupo $I=1$ a 7 anos $(N=59)$; grupo $I I=8$ a 15 anos $(N=47) ;$ grupo $I I I=\operatorname{acima} d e 16$ anos $(N=10)$.

Tentamos esclärecer as causas do efluxo elevado de enzimas da musculatura distrófica pelo estudo direto das atividades enzimáticas no tecido muscular. Com êsse estudo esperávamos verificar se determinados componentes estruturais da célula muscular são acometidos primàriamente e se existem pontos de partida específicos para determinados distúrbios do me- 
tabolismo celular ou, como admitem muitos autores, se o distúrbio primário reside na alteração da permeabilidade da membrana celular. Em nosso entender essas pesquisas só podem dar resultados satisfatórios se fôr dosado maior número de enzimas, suficiente para análise estatística significativa. Paralelamente deveriam ser feitos estudos histopatológicos.

Como base preliminar procedemos ao estudo espectral da atividade enzimática do músculo normal, determinando não apenas os valôres absolutos, mas também a distribuição de cada enzima nos diferentes componentes celulares (citoplasma, núcleo, mitocôndrios, microsomas). Pesquisamos um total de 25 enzimas nos homogeneizados de tecido muscular de 118 pessoas sem afecções musculares, em 145 amostras colhidas em pacientes com miopatias, na maior parte dos casos com distrofias musculares progressivas, e 28 amostras obtidas em pacientes com distrofias musculares de origem neural ou medular, sendo a atividade enzimática referida em relação à grama de proteína contida no estrato.

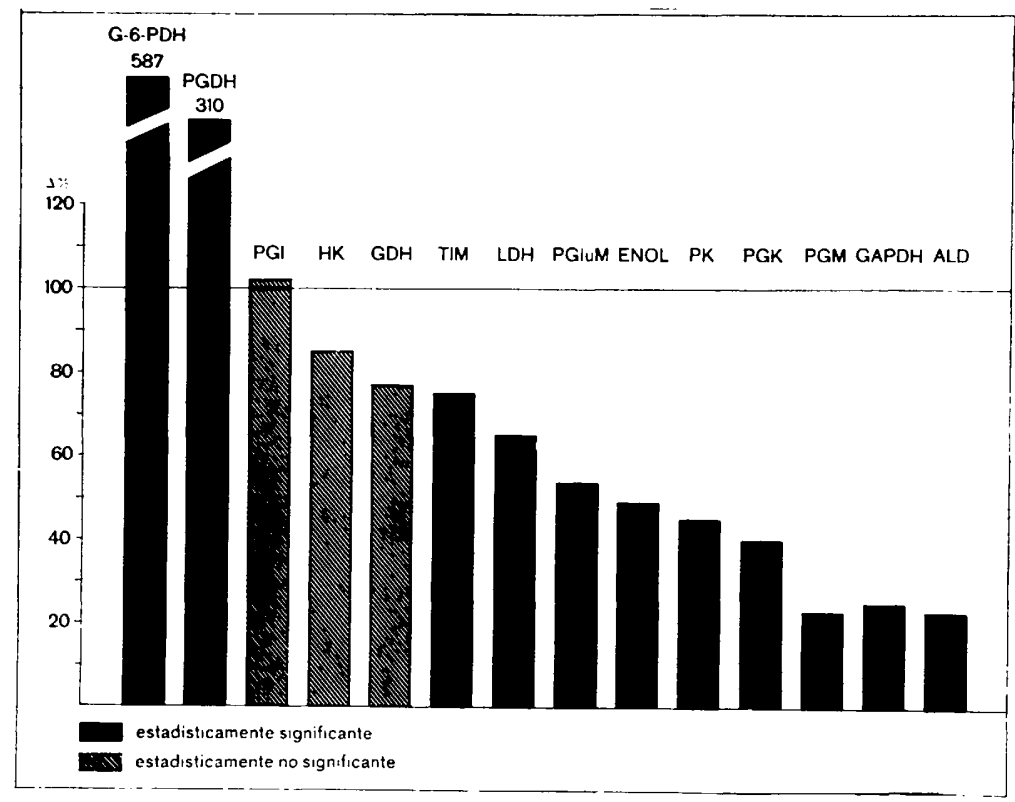

Fig. 4 - Desvio percentual, em relação aos valôres médios normais $(=100)$ obtidos em 35 individuos sadios, dos teores enzimáticos musculares (enzimas da glicólise) em 145 casos de distrofia muscular progressiva.

Nesta exposição sumária não cabe entrar em pormenores quanto à metodologia ou quanto à significação das diferentes enzimas e sua localização estrutural, nem ventilar questōes ainda discutiveis sôbre a interpretação de resultados isolados. No atinente ao assunto que está sendo relatado e ba- 
seados em pesquisas que já referimos em trabalhos anteriores $7,8,9,13$, salientaremos apenas três resultados gerais.

1) Com o progredir da distrofia, a maior parte das enzimas do tecido muscular sofre uma diminuição progressiva de sua atividade. Isso se dá tanto em relação com as enzimas que interferem no processo de glicólise (fig. 4), como nas que atuam nos processos de oxidação tissular e nas chamadas enzimas de ligação (fig. 5). O aumento de atividade de algumas enzimas (G-6-PDH, PGDH, GIDH, ICDH) é explicável pelo seu alto teor nos tecidos adiposo e conjuntivo que progressivamente substituem o tecido muscular. Assim, não pode ser provada a suposição de qụe, no ciclo Embden-Meyerhof de decomposição dos hidratos de carbono e que é impedido pela falta de enzimas, ocorra aumento do ciclo do fosfato de pentose. Algumas enzimas (GOT, GPT, PGI) apresentam, nas fases iniciais do processo muscular, um aumento de atividade que, até o momento, não pôde ser suficientemente explicado.

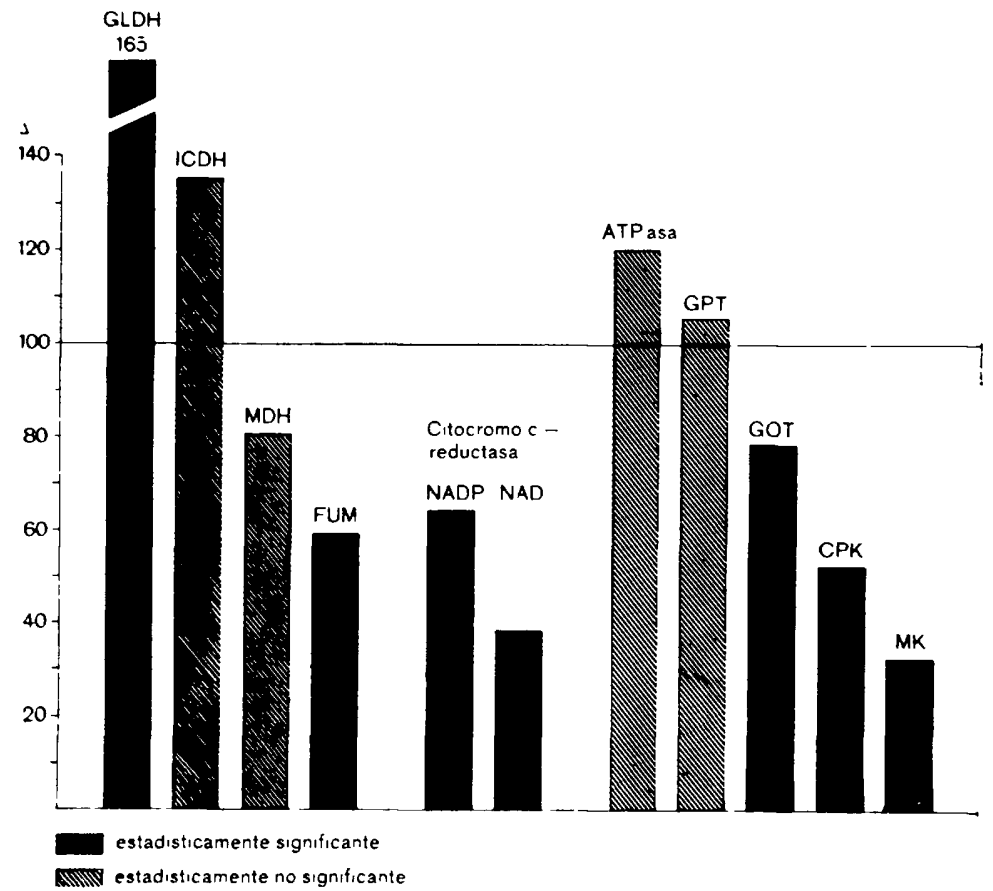

Fig. 5 - Desvio percentual, em relação aos valôres médios normais (= 100) obtidos em 35 individuos sadios, dos teores enzimáticos musculares (enzimas da oxidação e de função respiratória) em 145 casos de distrofia muscular progressiva.

2) O estudo comparativo das atividades das enzimas tissulares nas três formas de distrofia muscular progressiva hereditária mostra apenas diferenças insignificantes e inespecíficas. 
3) Nas distrofias musculares de origem medular as alterações das atividades enzimáticas tissulares são idênticas às encontradas nas distrofias musculares progressivas miopáticas. Para esta comparação utilizamos material de biopsias feitas em 12 casos de distrofia pseudo-miopática tipo Kugelberg-Welander e em um grupo de pacientes com distrofia muscular tipo Duchenne, com idades e fases evolutivas comparáveis.

Dêsses resultados devemos concluir que as alterações das atividades enzimáticas até agora estudadas nas distrofias musculares nada têm de específico. Provàvelmente são três os fatôres determinantes das variações nos aumentos da atividade enzimática verificadas no sôro sangüíneo nos diferentes tipos de distrofia muscular: a idade dos pacientes, a intensidade do prccesso, a quantidade de massa muscular acometida. Nos casos de distrofias musculares de origem neural ou medular, as elevações mais discretas dos teores de sôro-enzimas podem ser explicadas pelo fato de que, nesses casos, é relativamente pequena a participação de fibras musculares ainda não atrofiadas embora já acometidas.

A pesquisa das atividades enzimáticas poderia ter utilidade prática no contrôle de medidas terapêticas. Por isso usamos essa pesquisa em pacientes com distrofia muscular progressiva submetidos à terapêutica anabólica ${ }^{11}$. Durante algum tempo foi atribuido a êsse tratamento um efeito favorável, para o que contribuiu uma comunicação de Dơwben sôbre os bons resultadoz obtidos com a administração de hormônios anabolizantes associados à digitoxina. Em 55 de nossos casos êste tratamento não proporcionou qualquer resultado favorável. Além disso, pudemos demonstrar que a administração de digitoxina agrava significativamente o déficit de enzimas tissulares. Conseqüentemente, o aumento das enzimas no sôro sangüineo provém, não sòmente do aumento da síntese das proteínas enzimáticas, mas também da ação prejudicial do medicamento sôbre a musculatura. Por isso, consideramos inaceitável e perigosa esta terapêutica, cuja utilidade também não foi confirmada em vários centros norte-americanos.

A pesquisa das atividades enzimáticas no sôro sangüineo tem significado para o diagnóstico precoce, uma vez que, como o demonstraram vários autores (Aebi e col., Pearson e col., entre outros) os teores enzimáticos pcdem se apresentar elevados muito tempo antes que se manifeste, clinicamente, a distrcfia muscular. A suposição, expressa por Pearson e col., de que o distúrbio, nas distrofias musculares progressivas hereditárias, existe dєsde o nascimento, foi confirmada por nós pela primeira vez ${ }^{10,12}$. A mãe de um menino que estava sendo observado por nós por apresentar distrofia muscular progressiva tipo Duchenne, deu à luz a outro menino em 1963; esta criança tem, hoje, 3 anos de idade e até agora nāo apresentou qualquer indício de distrofia muscular; no entanto, desde seu nascimento a atividade enzimática no sôro sangüíneo é elevada. Entre o primeiro e o segundo anos de idade os teores enzimáticos alcançaram os valôres mais elevados, sendo mesmo superiores, para algumas enzimas, aos valôres mais altos que obtivemos $\epsilon \mathrm{m}$ mais de 1.000 dosagens feitas em pacientes com distrofias musculares progressivas (fig. 6). Parece, portanto, que a elevação máxima 
das atividades sôro-enzimáticas ocorre antes que surjam as manifestaçôes clínicas, ao menos na distrofia muscular progressiva tipo Duchenne. O proveito prático que se pode tirar dessa verificação reside no fato de que, nas famílias nas quais existirem crianças com distrofia muscular progressiva, logo depois do nascimento de um nôvo filho será possivel, mediante dosag€ns da atividade sôro-enzimática, dizer se essa criança será normal, ou não.

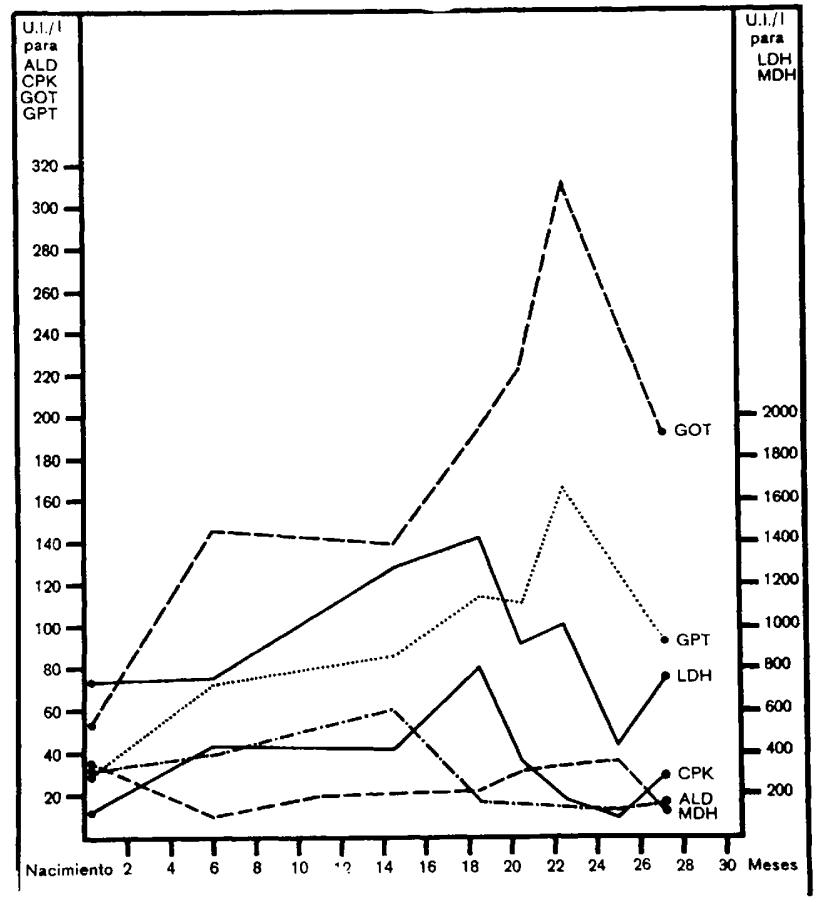

Fig. 6 - Oscilaçōes dos teores sôro-enzimáticos em um caso de distrofia muscular progressiva tipo Duchenne (fase pré-clinica) durante os primeiros 28 meses de vida.

Tivemos oportunidade de correlacionar as atividades sôro-enzimáticas com exames histopatológicos nessa mesma criança, aos 7 meses de idade, confirmando o que já era previsto pelos resultados das dosagens sôro-enzimáticas. O exame histopatológico mostrou que, mesmo antes da fase em que é máximo o teor das enzimas sangüíneas, pode haver degeneração e necrose de fibras musculares. Esta observação põe em xeque a idéia, expressa por alguns estudiosos, de que a passagem precoce das proteínas enzimáticas, da musculatura para o sôro sangüíneo, seja devida a um distúrbio da permeabilidade da membrana da célula muscular, distúrbio êste que iniciaria o processo. É claro que a demonstração de que, desde o início do processo, há degeneração e decomposição das fibras musculares impõe outra explicação para o aumento precoce do teor das sôro-enzimas. 
Vários estudos 1, 4, 5, 9, 18, 19, 21, 23 também mostraram que, nas distrofias musculares progressivas tipo Duchenne, de hereditariedade x-cromosômica, podem ocorrer aumentos da atividade enzimática no sôro sangüineo de transmissores femininos heterozigotos do distúrbio genético, isto é, em mães que, aprentemente sadias, geram filhos doentes. As primeiras comunicações feitas a êste respeito deram a esperança de que seria possível despistar, com segurança, as mulheres transmissoras, permitindo ministrar conselhos eugênicos em tempo hábil. Entretanto, nossas pesquisas, secundando as de Pearson e outros autores, mostraram que aumentos da atividade sôro-enzimática ocorrem em apenas cêrca de $50 \%$ das mães certamente condutoras dos gens anormais. Biopsias feitas em uma série de mães aparentemente sadias e com teores sôro-enzimáticos normais mostraram que algumas fibras musculares isoladas apresentavam alterações típicas da distrofia muscular.

A teoria em mosaico de Mary Lion explica êste fato. De acôrdo com esta teoria, nas células somáticas de pessoas do sexo feminino, um dos dois $\mathrm{x}$-cromosomas é inativado, de maneira que, em média, metade das células contem um e a outra metade contém o outro dos x-cromosomas. De acôrdo com esta concep̧̧ão, nos tipos heterozigotos que dispõem de um gen mutado e de um alelo sadio, a metade das fibras musculares será distrófica. Em tais circunstâncias as fibras sadias restantes serão suficientes para suprir a função e impedir que a moléstia se manifeste clinicamente. Se as proporções da mistura forem condicionadas pelo acaso, deverão ser admitidas dispersões para ambos os lados, conforme a curva de distribuição de Gauss, isto significando que em certos casos poderão predominar, ou não, as fibras com tendência à distrofia. Por êsse mecanismo pode ser explicada a variabilidade dos resultados na pesquisa das sôro-enzimas em mães transmissoras. No entanto, é de supor que a idade, nos heterozigotos, desempenhe algum papel, pois é plausivel que, com o avançar da idade, fibras de formação defeituosa sejam progressivamente eliminadas, com o que diminuirão progressivamente os teores das sôro-enzimas.

Esta hipótese é apoiada pelas recentes pesquisas de Rotthauve e Kowalewski, que encontraram teores sangüíneos elevados de creatinofosfoquinase sỏmente em 12 de 22 mulheres adultas seguramente portadoras da enfermidade, ao passo que, em um grupo de pessoas do sexo feminino com menos de 15 anos de idade, tôdas apresentavam teores sôro-enzimáticos elevados. Portadoras seguras com esta idade sāo encontráveis sòmente em famílias nas quais ocorre distrofia muscular hereditária x-cromosômica, relativamente rara e de decurso lento, que foi descrita por Becker e Kiener e na qual os filhos podem ser acometidos, ou não, sendo as filhas indenes mas infalivelmente portadoras da moléstia.

Quando, na pesquisa das atividades sôro-enzimáticas de duas ou mais irmãs, forem encontrados valôres elevados de creatinofosfoquinase, é muito provável que se trate de heterozogitos que devem admitir a possibilidade de transmitir a moléstia a seus filhos. Quando os teores de sôro-enzimas forem normais em irmãos de individuos doentes, êstes irmãos devem ser considerados como sadios, não correndo o risco de transmitir a moléstia a seus 
descendentes. Incerta continua a ser a situação de irmãs dos pacientes com distrofia muscular progressiva tipo Duchenne nas quais as sôro-enzimas se apresentarem com teores normais. Os estudos neste setor ainda são insuficientes para, em tais circunstâncias, afirmar que elas estão isentas da tara hereditária. Em tais casos a biopsia miscular poderá contribuir para melhor esclarecimento.

Finalizando, podemos dizer que os estudos da enzimopatologia das distrofias musculares, embora ainda não tenham esclarecido a causa destas afecções, enriqueceram nossos conhecimentos quanto à patogenia e servem de base para estudos em outras direções. As pesquisas no terreno da enzimologia, embora não tenham satisfeito a tôdas as esperanças que nelas foram depositadas, têm grande valor no que tange ao diagnóstico e ao prognóstico, assim como à biologia hereditária das distrofias musculares progressivas.

\section{RESUMO}

Depois de apresentar os dados clínicos e genéticos relativos a 221 casos de distrofia muscular progressiva (125 casos do tipo Duchenne, 63 do tipo cintura pélvica e 25 do tipo fácio-escápulo-umeral), os autores analisam os resultados das dosagens sôro-enzimáticas que fizeram; em alguns casos foram pesquisas também as atividades de 25 enzimas em homogeneizados de tecido muscular. Os mesmos exames foram feitos em casos de miopatias de outra etiologia e de distrofias musculares neuropáticas e mielopáticas. Foi verificado que o teor das sôro-enzimas aumenta em tôdas as formas de distrofia muscular progressiva hereditária. No tipo Duchenne as atividades enzimáticas são elevadas desde o nascimento das crianças acometidas, precedendo o aparecimento da sintomatologia clínica. Com o progredir da moléstia e com o decorrer dos anos os teores sôro-enzimáticos tendem a diminuir, podendo reduzir-se aos valôres normais nas fases finais da moléstia. No tecido muscular não existe diferença significante, no que respeita à composição enzimática, entre os diversos tipos de distrofia muscular progressiva e hereditária. Com exceção de poucas enzimas cuja atividade é maior nos tecidos conjuntivo e adiposo que progressivamente substituem o tecido muscular que entra em atrofia, o teor das mio-enzimas diminui com o progredir da moléstia, como expressão do crescente esgotamento do citoplasma da célula muscular. Nas distrofias musculares neuropáticas e mielopáticas as alterações são idênticas, embora de menor intensidade. Algumas diferenças quantitativas podem ser explicadas pela idade dos pacientes e pela intensidade do processo. A mesma diferença pode ser demonstrada mediante exames histopatológicos: nas formas que acometem crianças (Werdnig-Hoffmann) as fibras musculares ainda não denervadas se apresentam com aspecto normal, áo passo que, nas formas do adulto (Kugelberg-Welander), possivelmente pelo desgaste provocado pelos esforços musculares, tais fibras freqüentemente apresentam alterações idênticas às encontráveis nas distrofias musculares miopáticas hereditárias. 


\section{SUMM $\triangle R Y$}

Differential diagnosis of muscular dystrophies with special reference to enzymatic activities

The enzymes ALD, CPK, GOT, CPT, LDH and $\mathrm{MDH}$ were studied in the serum of 221 patients suffering from progressive muscular dystrophy and in 43 cases of infantile and pseudomyopathic muscular dystrophy. Besides, the activity of 25 enzymes was measured in the muscular tissue. All findings were statistically revised. Serum enzymes are increased in all of the 3 types of muscular dystrophy; in most cases of the Duchenne type, however, many times over the other types. The difference is not specific, but can be explained by the considerably more marked progression of muscle degeneration in the Duchenne type. The enzyme increases are already existent at birth and reach a maximum before clinical manifestation of the disease. The activities of all serum enzymes decrease with longer duration of the disease. This phenomenon also occurs in the majority of all serum enzymes. Up to now, modifications indicating a specific abnormality of metabolism could not be stated. Likewise in spinal muscular atrophies of the Kugelberg-Welander type, there appear the same enzyme losses in the muscle and significant increases of the enzyme activities in serum can be demonstrated. This does not apply to the infantile forms of Werdnig-Hoffmann type and this fact might be explained by the almost complete motorial inactivation. The hypothesis that the efflux of enzymes from the muscular cell might point to a disordered membrane permeability as initial process of muscular dystrophies, is likewise refuted by finding necrotic muscular fibers, already in the earliest preclinical stage of the disease. The serum enzyme findings are of limited value for establishing a clinical differential diagnosis. Only extremely marked increases of activity do reliably point. to the Duchenne type.

\section{REFERENCIAS}

1. AEBI, U.; RICHTERICH, H.; STILLHART, H.; COLOMBO, J. P. \& ROSSI, E. - Progressive Muskeldystrophie: Serumenzyme bei der Muskeldystrophie im Kindesalter. Acta paediat. helv. 16:543, 1961.

2. BECKER, P. E. \& KIENER, F. - Eine neue x-chromosomale Muskeldystrophie. Arch. psychiat. Nervenkr. 193:427, 1955.

3. DREYFUS, J. C. \& SCHAPIRA, G. - Enzimes musculaires et sériques en pathologie musculaire. In Enzymatische Regelungen in der Klinik - A. Gigon \& H. Ludwig edit. Benno Schwabe Co., Basel-Stuttgart, 1961.

4. DREYFUS, J. C.; SCHAPIRA, G. \& DEMOS, J. - Etude de la creatinequinase sérique chez les myopathes et leurs familles. Rev. franç. Etud. Clin. Biol. 5: $384,1960$.

5. DUBOWITZ, V. - Myopathic changes in a muscular dystrophy carrier. J. Neurol. Neurosurg. Psychiat. 26:322, 1963. 


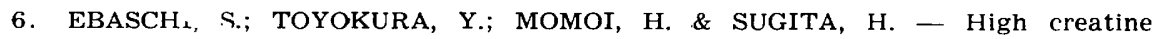
phosphokinase activity of sera of progressive muscular patients. J. Biochem. (Tokyo) 46:103, 1959.

7. HEYCK, H.; LAUDAHN, G. \& LUDERS, C. J. - Fermentaktivitaetsbestimmungen in der gesunden menschlichen Muskulatur und bei Myopathien: Enzymaktivitaetsveraenderungen im Muskel bei Dystrophia musculorum progressiva. Klin. Wschr. 41:500, 1963.

8. HEXCK, H. \& LAUDAHN, G. - Fermentaktivitaetsbestimmungen in der gesunden menschlichen Muskulatur und bei Myopathien: Enzymaktivitaetsveraenderungen im Serum bei Dystrophia musculorum progressiva. Klin. Wschr. 41:905, 1963.

9. HEICK, H. \& LAUDAHN, G. - Fermentchemische Serumbefunde bei Myopathien. In Myopathien - R. Beckmann edit. Georg Thieme Verlag, Stuttgart, 1965.

10. HEYCK, H.; LAUDAHN, G. \& CARSTEN, P. M. - Enzymaktivitaetsbestimmungen bei Dystrophia musculorum progressiva: Die Serumenzymkinetik im praeklinischen Stadium des Typus Duchenne waehrend der ersten 2 Lebensjahre. Klin. Wschr. 44:695, 1966.

11. HEICK, H.; LAUdAHN, G.; LUdERS, C. J.; MULleR-STEPHAN, H. \& SCHMIDTPETER, P. - Anabolic steroids and digitoxin in the treatment of progressive muscular dystrophy. Acta paediat. scand. 54:205, 1965.

12. HEYCK, H.; LUDERS, C. J. \& LAUDAHN, G. - Beitrag zur Dystrophia musculorum progressiva: Histologische Befunde im praeklinischen Stadium der Dystrophie musculorum progressiva Typ Duchenne. Klin. Wschr. 44:813, 1966.

13. LAUDAHN, G. \& HEICK, H. - Fermentaktivitaetsbestimmungen in der gesunden menschlichen Muskulatur und bei Myopathien: Enzymmuster und intracellulaere Verteilung von Enzymen im gesunden Skelett-muskel. Klin. Wschr. $41: 493,1963$.

14. LEVY, J. A. - Contribuição para o diagnóstico diferencial da distrofia muscular progressiva. Arq. Neuro-Psiquiat. (São Paulo) 22:73, 1964.

15. LION, M. - Gene action in the $x$-chromosome of the mouse. Nature (London) 190:372, 1961.

16. MITTELBACH, F. - Die Begleitmyopathie bei neurogenen Atrophien. Monographien aus dem Gesamtgebiet der Neurologie und Psychiatrie, Heft 113 . Springer Verlag, Berlin-Heidelberg-New York, 1966.

17. PEARSON, C. M. - Histopathological features oi muscle in the preclinical stages of muscular dystrophy. Brain 85:109, 1962.

18. PEARSON, C. M.; FOWLER, W. M. \& WRIGHT, ST. W. - X-chromosome mosaicism in females with muscular dystrophy. Proc. nat. Acad. Sci. 50:24, 1963.

19. ROTThAUWE, H. W. \& KOWALEWSKI, S. - Die Bedeutung der Serum-Kreatin-Phosphokinase und der Serum-Aldolase fuer die Identifizierung von Heterozigoten der recessiv x-chromosomalen Formen der progressiven Muskel-dystrophie. Klin. Wschr. 43:150, 1965.

20. SIBLEY, J. A. \& LEHNINGER, A. L. - Determination of aldolase in animal tissues. J. Biol. Chem. 177:859, 1949. 
21. STEPHENS, J. \& LEWIN, E. - Serumenzyme variations and histological abnormalities in the carrier state in Duchenne dystrophy. J. Neurol. Neurosurg. Psychiat. 28:104, 1965.

22. THOMPSON, R. A. \& VIGNOS, P. J. - Serum aldolase in muscle disease. Arch. intern. Med. (AMA) 103:551, 1959.

23. WALTON, J. N. - Muscular dystrophy: some recent advances in knowledge. Brit. med. J. 1:1271-1724 e 1344-1348, 1964.

Clayallee 249, Berlin 37, Deutschland. 